\title{
La cadena de valor del vídeo musical: el videoclip en el circuito comercial de las industrias culturales
}

Jennifer Rodríguez-López Universidad de Huelva

Ignacio Aguaded-Gómez Universidad de Huelva

\section{Palabras clave}

Vídeo musical; industria discográfica; industrias culturales; cadena de valor; promoción; distribución.

\section{Resumen}

El vídeo musical forma parte de las industrias culturales como mercancía producida por las compañías discográficas, partiendo de un tema musical para la construcción de un producto audiovisual susceptible de venta y al mismo tiempo como impulsor de otros artículos como el disco. Esta naturaleza dual convierte al videoclip tanto en un producto cultural en sí mismo como en una herramienta de promoción para otros artículos de la industria del entretenimiento. El presente artículo plantea la cadena de valor de la industria discográfica a través de los distintos agentes implicados para su posterior extrapolación al vídeo musical como producto de dicha industria cultural. Su objetivo es mostrar la estructura interna de las compañías fonográficas durante las fases de creación, comercialización y distribución del producto así como comparar las cadenas de valor del disco y el videoclip así como diferencias los productos físicos de aquellos creados digitalmente y distribuidos de forma on-line. La metodología aplicada se basa en la descripción y comparación de ambos productos de la industria discográfica. Como conclusión principal se defiende la autonomía del formato clip, creando su propia cadena de valor y estableciéndose como un producto independiente del resto de mercancías producidas por la industria del disco. 


\title{
The Music Video Value Chain: Music Video into Cultural Industries' Commercial Circuits
}

\section{Keywords}

Music Video; Phonographic Industry; Cultural Industries; Value Chain; Promotion; Distribution.

\begin{abstract}
The music video is part of the cultural industries as a commodity produced by record companies. It is based on a theme song for the construction of an audiovisual product and at the same time sold other items like disk. This dual nature makes the music video a cultural product itself and a promotional tool for other items in the entertainment industry. This paper raises the value chain of the music industry through various agents involved for subsequent extrapolation to the music video as a product of the culture industry. It aims to show the internal structure of the phonographic industry during the phases of development, marketing and distribution of the product and compare the value chains of the disc and the music video and differences of those physical products digitally created and online distributed. The methodology is based on the description and comparison of both products of the record industry. The main conclusion is a defense to the music videos's autonomy as format, with the creation of its own value chain and its establishing as an independent product from other commodities produced by the phonographic industry.
\end{abstract}

\begin{abstract}
Autores
Jennifer Rodríguez-López [jennmas_7@hotmail.com] es doctora en Comunicación Audiovisual, máster en Patrimonio Histórico y Natural y licenciada en Humanidades por la Universidad de Huelva (España). Ha trabajado como técnico en Patrimonio Universitario en dicha institución onubense y ha participado en un proyecto financiado por la Junta de Andalucía sobre alfabetización mediática.

Ignacio Aguaded-Gómez [ignacio@aguaded.es] es catedrático de universidad del departamento de Educación de la Universidad de Huelva (España). Presidente del Grupo Comunicar, colectivo veterano en España en educomunicación, y director de la revista científica iberoamericana Comunicar (indexada en JCR, ERIH, Scopus...). Es además director del grupo de investigación Ágora, responsable de múltiples proyectos de investigación nacionales e internacionales y la dirección de numerosas tesis doctorales. Es director del Máster Internacional Interuniversitario de Comunicación y Educación Audiovisual (UNIA/UHU).
\end{abstract}




\section{La cadena de valor en las industrias culturales}

La cadena de valor se define como el conjunto interrelacionado de actividades creadoras de valor que interfieren en un producto desde su fase de creación hasta la difusión del mismo. En dicha cadena intervienen distintos agentes que añaden valor al producto final a partir de determinadas acciones basadas en la creatividad, la originalidad y el know-how. Por su parte, las industrias culturales se han definido de forma general como aquellas que elaboran productos procedentes de la cultura transformados durante dicho proceso en mercancías destinadas a la explotación económica. La creación y difusión de contenidos digitales está transformando las industrias actuales así como sus cadenas de valor. La industria discográfica ha evolucionado en este sentido incorporando productos digitales como el vídeo musical así como aplicando nuevos modelos de negocio que incluyen la creación y la distribución en la red, creación de nuevos formatos, estrategias empresariales, nuevos agentes, etc.

Así, el vídeo musical se encuentra inserto en el entramado de las industrias culturales como mercancía producida por ellas, partiendo de un tema musical para la construcción de un producto audiovisual susceptible de venta y al mismo tiempo como impulsor de otros artículos como el disco. Esta naturaleza dual convierte al videoclip tanto en un producto cultural en sí mismo como en una herramienta de promoción para otros artículos de la industria del entretenimiento. Por ello, se define como un producto creado por la industria discográfica para la promoción de sus artistas, adaptando el lenguaje cinematográfico y publicitario para la creación de un estilo propio en la fase de producción y adoptando el medio televisivo en la fase de difusión, no siendo esta la única opción de distribución posible. En este sentido, Sedeño (2008: 755) define los vídeos musicales como producciones «fruto de la elaboración intencional de un conjunto de entidades empresariales, económicas y sociales para cubrir unos objetivos lucrativos, con el consiguiente peso e influencia socio-político-económicos» y, por tanto, productos de las industrias culturales.

\section{Metodología}

El principal objetivo de este artículo es el de comparar la producción de valor de la industria discografía durante el proceso de creación del disco en primer lugar y del vídeo musical como segundo producto asociado al artista. Para ello, la metodología seguida se basa en la descripción para su posterior comparación de cada uno de los componentes de la cadena de valor. Este método se define como el procedimiento de la comparación sistemática de casos de análisis que en su mayoría se aplica con fines de generalización empírica y de la verificación de hipótesis. Ariza y Gandini (2012: 500) afirman que se basa en la «descripción y la explicación de las condiciones y los resultados semejantes y diferentes (usualmente estos últimos), entre unidades sociales grandes, naciones, sociedades y culturas». Estas autoras puntualizan que el método comparativo también puede ser entendido como «el análisis sistemático de observaciones extraídas de dos 
o más entidades macrosociales - o de varios momentos en la historia de una sociedad-para analizar sus semejanzas y diferencias e indagar sus causas». En este artículo, la comparación se aplica a dos casos, el disco y el vídeo musical como los dos productos principales creados, comercializados y distribuidos por la industria discográfica, inserta en el circuito de las industrias culturales.

Para conseguir la finalidad propuesta en este estudio se ha realizado una comparativa de ambas realidades - disco y vídeo musical- a partir de dos partes: la primera de ellas se basa en la descripción de cada uno de estos productos, mientras que en la segunda se desarrolla una comparativa en torno a las tres fases de producción: creación, comercialización y distribución, a partir de los agentes implicados en cada una de ellas así como de las acciones realizadas.

\section{La cadena de valor del disco}

La industria discográfica se define como una industria cultural cuya actividad productiva se basa en la reproducción masiva de piezas musicales desarrolladas por los artistas. Así, la explotación económica se basa en la creación y comercialización de dichas piezas artísticas transformadas en bienes tangibles y servicios con los que acceder al mercado y competir con el resto de mercancías. Además de estos productos, la industria musical cuenta con los derechos de autor, las licencias y otras formas de explotación de la propiedad intelectual para la obtención de beneficios económicos.

La mercancía tradicional de la industria discográfica es el disco. Este producto tiene una esencia artística además de económica lo que requiere un proceso de elaboración basado en una primera etapa de creación y dos etapas posteriores de comercialización y distribución. Frith (1980: 95) subraya que esta industria «se apoya en una inversión de capital comparativamente pequeña por producto, pero existe una intensa competición entre productos, y las ventas dependen de mecanismos de marketing que las compañías discográficas no controlan completamente». La producción discográfica implica en la elaboración de discos y en la construcción de su valor a distintas personas entre las que se encuentran los músicos, los directores artísticos, los managers, los editores, los productores y los promotores, entre otros. Estos agentes son los encargados de dotar al producto de valor artístico, hecho apoyado por la promoción a partir de la radio, las discotecas, las actuaciones en directo, la prensa especializada y las tiendas de discos. En la actualidad, se suma a estos mecanismos de difusión las webs y plataformas de divulgación y descarga de contenidos musicales. El autor (Frith, 1980: 111) afirma que «los discos son el resultado de la colaboración de diversas formas de trabajo», aplicable también al vídeo musical que como mercancía de la industria musical se inserta dentro de la promoción de los discos pero al mismo tiempo se erige como producto independiente necesitado de la misma cadena de valor (Fig. 1), con un presupuesto asignado. 


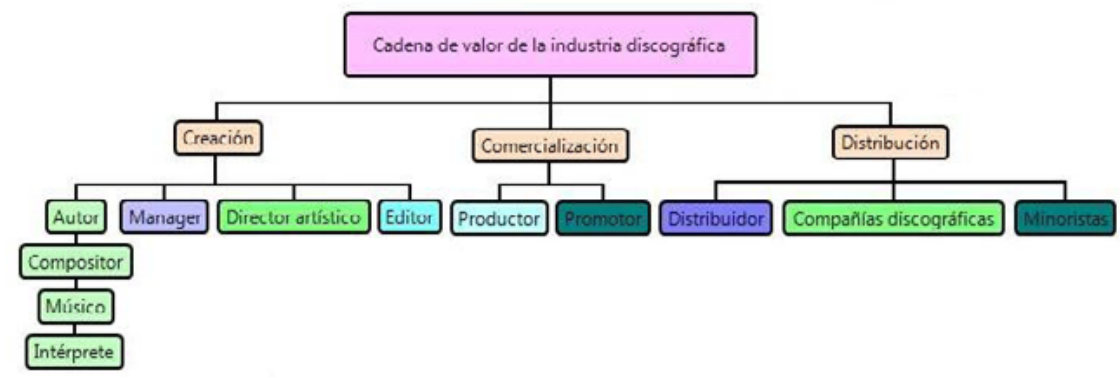

Figura 1. La cadena de valor de la industria discográfica (Fuente: Elaboración propia)

El proceso se inicia con la creación. En esta etapa interviene en primer lugar el autor, bajo cuya noción se engloba a todos los autores artísticos que contribuyen en la creación de la pieza musical: compositor, músico e intérprete. Así, el compositor hace referencia a la persona que crea la letra y la estructura musical de la canción, mientras que el músico le da forma completando la pieza final. El intérprete es el artista que ejecuta la actuación para la grabación del disco y quien será la cara visible frente al público. Estos tres agentes pueden coincidir en una misma persona o realizar su tarea de forma independiente. El artista comienza a recibir beneficios - denominados regalías - cuando los costes de producción del disco se han cubierto así como un porcentaje de los gastos de la producción de los vídeos musicales.

El manager es el intermediario entre el artista y la compañía discográfica. Es el encargado de poner en contacto a su representado con las compañías en busca de un contrato para la grabación de un disco y de defender los intereses del músico. Trata de conseguir la comercialización del producto creado por el autor a quien representa frente a la industria, introduciéndole en el circuito del mercado fonográfico. Así, se ocupa del asesoramiento, las relaciones con la prensa, la promoción y la publicidad y como nexo con la compañía discográfica y los editores musicales. Se encarga principalmente de los aspectos económicos asociados a la creación musical, así como de hacer cumplir el contrato por parte de la compañía discográfica.

La persona encargada del filtrado de músicos por parte de la compañía discográfica es el director artístico o A\&R (Artists and Repertoir), responsable de la elección de los autores que serán comercializados bajo el sello discográfico. Sus funciones se definen por la elección de los artistas, su conservación y la selección de los discos que se van a producir. Buscan talentos potenciales a través de audiciones, maquetas y actuaciones para encontrar nuevos artistas susceptibles de convertirse en productos vendibles masivamente. El director artístico debe asegurar que el artista elegido será económicamente beneficioso para que el 
sello discográfico haga frente a la inversión que supone la producción del disco. Debe valorar los futuros ingresos que reportará el músico para hacer viable la apuesta económica.

Asimismo, el editor se encarga de explotar el potencial comercial de la pieza. Frith (1980: 105) lo define como una fuente de material, ya que es un nexo entre el autor de las canciones y el artista que graba, son empleadores de autores, en ocasiones, a través de su propio sello independiente. Otra de sus funciones es la de controlar y administrar los derechos de una canción que ha sido grabada e interpretada, controlando las ganancias obtenidas a partir del uso y venta de las canciones. De este modo, el editor se ocupa de controlar y defender el uso que se hace de una canción en emisoras de radio, salas de conciertos, cines, discotecas, en televisión y actualmente también en internet, con el fin de recaudar los beneficios procedentes de los derechos de propiedad intelectual.

La fase de comercialización se inicia con la figura del productor, responsable de la producción real del disco, de su registro y edición para la creación de una mercancía tangible, atractiva y vendible. Sus tareas son tanto musicales como administrativas, ya que trata de coordinar en el estudio al artista, los músicos y los ingenieros de sonido para la grabación del disco. Poseen un carácter creativo, ya que, como apunta Frith (1980: 109), «la importancia de su contribución a un disco es tal que los productores pueden hacerse más influyentes que los músicos a los que producen, y las compañías llegan a considerarlos como la fuente de un éxito de ventas». Sirven como ejemplos Brian Eno, Dr. Dre o Timbaland, entre otros.

Una vez finalizada la grabación del disco, este debe convertirse en un objeto de consumo. Así, el fabricante se ocupa de la manufacturación de los discos y de la producción de las copias para su posterior comercialización y distribución. No debe obviarse el papel fundamental de este agente ya que, como apunta Frith (1980: 111), «si los elementos básicos son la capacidad de los músicos, el capital de las compañías discográficas y las obras musicales, el valor del producto terminado depende de otros elementos - productores e ingenieros, trabajadores en las plantas de prensado, diseñadores de cubiertas e impresores-», que convierten la idea en un objeto físico y material para su posterior venta.

Cada compañía discográfica cuenta con un área de publicidad destinada a dar a conocer a los artistas y nuevos lanzamientos a través de la prensa especializada, la radio, la televisión, los vídeos musicales, la difusión en internet mediante la publicidad viral entre otras técnicas, las actuaciones en directo, las firmas de discos, etc. El promotor gestiona las funciones relacionadas con la promoción tanto del artista como del nuevo disco con el objetivo de asegurar su venta en el mercado y su posterior fidelización de consumidores para la adquisición de futuros productos. En el caso del vídeo musical es frecuente que las compañías discográficas o los propios artistas recurren a productoras independientes para su producción. Como señala Sedeño (2008: 755) «la industria discográfica encarga 
realizar un videoclip a una agencia o productora audiovisual como herramienta promocional, pieza clave inserta en una campaña de lanzamiento de un tema musical de un determinado cantante». Según la autora, durante este proceso el clip se somete a pautas de estandarización en relación a su estética, influida por el film y el spot y también de socialización sobre los contenidos, ya que deben llegar al máximo público posible para conseguir el índice de ventas esperado.

Por último, la fase de distribución se inicia con los distribuidores, quienes organizan esta tarea para hacer llegar la mercancía a todos los minoristas, es decir, los comercios que se ocupan directamente de la venta del disco al consumidor. Las tiendas especializadas y las grandes superficies suponen el último eslabón en la cadena de valor, vinculando a la industria con el cliente de forma directa. En ocasiones, los minoristas también actúan como filtro, seleccionando los productos que serán vendidos en sus establecimientos. En la actualidad, la distribución a través de los minoristas es cada vez más limitada a favor de los sitios web dedicados a la venta tanto de discos en formato físico como digital, sirviendo de ejemplo Amazon, donde el usuario puede adquirir todo tipo de artículos en su tienda virtual.

Las compañías discográficas coordinan y financian todos estos procesos y se ocupan de la comercialización del producto. Tienen como finalidad la promoción de los artistas viables, así como favorecer el consumo de los mismos por parte de los posibles compradores. Las principales industrias fonográficas de mayor peso internacional son Universal Music Group, Sony Music, EMI, BMG y Warner Music. Existen también pequeñas compañías discográficas de carácter independiente que, por tanto, cuentan con menor capacidad distributiva y un presupuesto más escaso para el lanzamiento de nuevos artistas. Actualmente, debido al abaratamiento de la fase de distribución consecuencia del desarrollo de las plataformas web de difusión de los contenidos digitales, las compañías independientes han aumento su visibilidad y producción, contando con numerosos artistas bajo su sello. En sus inicios, las compañías indies servían como creadoras de una infraestructura para los grupos y cantantes noveles hasta que comenzaban a darse a conocer y pasaban a engrosar las listas de artistas de las grandes compañías. En España surgen Elefant, BOA, Munster y Jabalina entre muchas otras, que tratan de dar cabida a todo tipo de géneros musicales en el mercado nacional.

\section{La cadena de valor del vídeo musical}

El vídeo musical nace con la concatenación de varios factores entre los que se encuentran el desarrollo de la tecnología vídeo y su implantación en televisión tras el auge de la música pop y rock entre los jóvenes. La tecnología vídeo permitió numerosos progresos en el registro y almacenamiento de imágenes, al mismo tiempo que contribuyó a la experimentación tanto industrial como artística. En este sentido, Pérez Ornia (1991: 127) sostiene que «cuando, a lo largo 
de los setenta, el rock y el pop se hacen imprescindibles en las programaciones de la televisión - como había sucedido antes en la radio - la industria de la música y de la televisión necesitan crear el formato de los videoclips, microrrelatos cinematográficos que ilustran las canciones con el fin de promover la venta de discos». El autor sostiene como origen la extensión de la música rock entre los jóvenes, con el consiguiente interés al respecto por parte de los programadores por incluir contenidos dirigidos a este sector del público. Como apunta Frith (2006: 100) «este fenómeno fue una causa y un efecto de los cambios en las estrategias de la programación introducidos en las grandes redes de la televisión musical, que ha observado un rejuvenecimiento progresivo de sus audiencias». La televisión fue consciente de dicho fenómeno y trató de impulsar contenidos enfocados hacia este target como perfil de consumidores de música. Así, el vídeo musical se construye a la vez como mercancía y como medio, insertándose en el ámbito de los medios de comunicación de masas.

De esta forma queda patente cómo el vídeo musical forma parte de la industria discográfica como producto promocional de un single y de un artista, apoyado en la nueva tecnología vídeo y en el circuito televisivo. Dentro de la industria discográfica el videoclip posee una naturaleza dual: por una parte, se constituye como un producto en sí mismo, producido y financiado por la industria musical; por otro lado, actúa como promotor de otros productos de dicha industria, lo que evidencia la relación del clip con la industria publicitaria ya que es la forma de difusión de los productos de la industria del disco más directa. Además se ha configurado como un formato habitual en la iconosfera que envuelve al individuo, pues el espectador consume el clip de un modo natural, inconsciente casi de su objetivo promocional. Como producto publicitario, el vídeo musical permite llegar a una audiencia múltiple, creando nuevas relaciones entre el emisor y los receptores. Como apunta Girard (1982: 30) «el vídeo permite a la vez la difusión para millones de espectadores, la redifusión para los aficionados y el archivado para los especialistas». Estos avances fueron adaptados por el vídeo musical para la creación de un producto de menor coste y mayor difusión de los contenidos de la industria discográfica. Dicha difusión del videoclip a través de la televisión y de internet supone una multirrecepción cada vez más masiva. El fenómeno de la redifusión ha evolucionado hacia la elección activa que suponen las plataformas digitales en la web 2.0 en las que el usuario selecciona directamente los contenidos que quiere visionar sin necesidad de esperar a que aparezcan en televisión, participando de un modo más activo en la difusión de los clips.

La cadena de valor tradicional ha sido alterada con la llegada de las nuevas tecnologías vinculadas a internet y el desarrollo de los contenidos digitales. Como mantiene Calvi (2006: 125) dicha cadena está incorporando nuevos elementos y además de la creación y la producción musical, «es necesario implementar nuevas infraestructuras tecnológicas de digitalización de la música, almacenamiento y distribución, derechos sobre los productos musicales», incidiendo en el aumento de los agentes implicados en la cadena de valor hacia, por ejemplo, 
las empresas de software y hardware. Por otra parte, la distribución se realiza en la actualidad a través también de plataformas de distribución comercial como los sitios web iTunes y Napster, que mantienen acuerdos de distribución de la música con las compañías discográficas. Calvi (2006: 125) señala que los nuevos modos de comercialización se basan en modelos históricos de financiación de las industrias culturales, lo que se traduce en «la financiación directa a través del pago por producto y la financiación indirecta por medio de la publicidad». Así, las compañías discográficas obtienen beneficios a partir de la descarga de música en internet previo pago, a través de la publicidad inserta en dichas plataformas de descarga y mediante la descarga de contenidos en dispositivos móviles. Se establecen así dos tipos de mercado - offline y online- que, sin embargo, no alteran la estructura de la industria musical.

El lugar ocupado por el vídeo musical en esta cadena de valor en la elaboración del CD como mercancía física se relaciona con la figura del promotor, encargado de la producción del videoclip como fórmula publicitaria en el lanzamiento de un single. Como subraya Fandos (1993: 94), «las compañías discográficas orquestan al mismo tiempo la grabación del disco y la grabación de vídeo-clips para su lanzamiento conjunto». Los singles son lanzados junto al vídeo musical, conscientes del potente poder seductor de las imágenes. La promoción clip se produce desde la producción del disco. Los fans esperan la salida de ambos productos, por lo que el vídeo musical se erige como un producto independiente de la industria discográfica, existiendo recopilaciones en DVD de vídeos musicales agrupados por grupo musical o director principalmente. Dicho agente contrata los servicios de un director a través de la compañía discográfica. De este modo, el vídeo musical se configura como un eslabón en la creación del valor del soporte físico creado por la industria. Sin embargo, el vídeo musical como producto independiente genera su propia cadena de valor (Fig. 2), cuyos elementos suelen coincidir con los asignados al disco.

Como se ha referido anteriormente, la fase de creación se inicia en la compañía discográfica bajo la responsabilidad del promotor. El vídeo musical es encargado a una productora audiovisual que asigna el proyecto a un director de videoclips. Es usual que el intérprete protagonice el videoclip aunque este puede construirse sobre una narración o concepto en el que no aparezca, ahondando más en un carácter artístico que promocional.

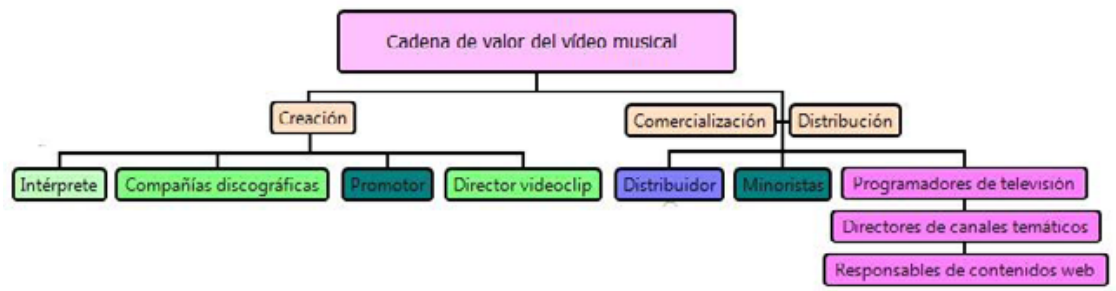

Figura 2. La cadena de valor del vídeo musical (Fuente: Elaboración propia) 
El vídeo musical se convierte en soporte físico al convertirse en formato de DVD con selección del trabajo de un director o de los vídeos musicales de un artista, una época o de un recopilatorio. De esta forma puede ser distribuido en los mismos comercios que el disco. Sin embargo, la naturaleza audiovisual del clip posibilita su distribución a través de otros medios como la televisión y las plataformas web destinadas a la descarga y visionado de vídeos tanto previo pago como de forma gratuita. Se incorporan de este modo nuevos agentes a la cadena de valor como los programadores de televisión, encargados de crear las parrillas de contenidos televisivos, los directores de canales monográficos, responsables de los clips que serán emitidos y, por tanto, potentes agentes de filtrado, así como los responsables de los páginas web, expertos también en mercadotecnia, coordinadores de la edición y tratamiento de los contenidos.

\section{Conclusiones}

Tras la descripción de ambas cadenas de valor, se presenta el análisis comparativo de los mismos. Así, en el cuadro expuesto a continuación (Fig. 3) se resumen las conclusiones extraídas tras la comparación del disco y el vídeo musical:

\begin{tabular}{|c|c|c|c|}
\hline \multicolumn{2}{|c|}{ Dimensiones } & $\begin{array}{l}\text { Caso 1: } \\
\text { Disco }\end{array}$ & Caso 2: \\
\hline \multirow[t]{2}{*}{ Fase 1: Creación } & Agentes & $\begin{array}{l}\text { Autor } \\
\text { Manager } \\
\text { Director artístico } \\
\text { Editor }\end{array}$ & $\begin{array}{l}\text { Intérprete } \\
\text { Compañía discográfica } \\
\text { Promotor } \\
\text { Director videoclip }\end{array}$ \\
\hline & Acciones & $\begin{array}{l}\text { Creación lintangible) } \\
\text { Representación } \\
\text { Filtración } \\
\text { Administración }\end{array}$ & $\begin{array}{l}\text { Creación (intangible) } \\
\text { Publicidad }\end{array}$ \\
\hline \multirow[t]{2}{*}{$\begin{array}{l}\text { Fase 2: Comercia- } \\
\text { lización }\end{array}$} & Agentes & $\begin{array}{l}\text { Productor } \\
\text { Promotor }\end{array}$ & Promotor \\
\hline & Acciones & $\begin{array}{l}\text { Producción (tangible) } \\
\text { Fabricación } \\
\text { Promoción }\end{array}$ & $\begin{array}{l}\text { Fabricación } \\
\text { Promoción }\end{array}$ \\
\hline \multirow[t]{2}{*}{$\begin{array}{l}\text { Fase 3: Distribu- } \\
\text { ción }\end{array}$} & Agentes & $\begin{array}{l}\text { Distribuidor } \\
\text { Comercios }\end{array}$ & $\begin{array}{l}\text { Programadores de televisión } \\
\text { Directores de canales temáticos } \\
\text { Responsables de contenidos web }\end{array}$ \\
\hline & Acciones & $\begin{array}{l}\text { Distribución } \\
\text { Filtración } \\
\text { Venta }\end{array}$ & Difusión \\
\hline
\end{tabular}

Figura 3. Comparativa entre las cadenas de valor del disco y el vídeo musical (Elaboración propia) 
Se exponen las diferencias existentes entre ambos productos en sus diferentes fases, ya que en la primera de ellas, la creación se basa en diferentes agentes creando en la primera un producto físico en la fase de distribución mientras que el vídeo musical se crea como producto intangible susceptible de ser difundido y distribuido de forma online. A diferencia del videoclip, el disco necesita de un soporte físico para su comercialización aunque en la actualidad son cada vez más mayoritarios nuevos modelos de distribución basados en la digitalización de los contendidos y su difusión y venta en plataformas como iTunes, Grooveshark y Spotify. En el siguiente cuadro (Fig. 4) se presentan las diferencias entre las cadenas de valor del medio físico (ejemplificado en el disco) y del medio online (a través del vídeo musical como paradigma):

\begin{tabular}{|l|l|l|}
\hline \multicolumn{1}{|c|}{ Dimensiones } & \multicolumn{1}{|c|}{ Cadena de valor del medio físico } & \multicolumn{1}{c|}{ Cadena de valor del medio on-line } \\
\hline $\begin{array}{l}\text { Fase 1: } \\
\text { Creación }\end{array}$ & $\begin{array}{l}\text { Composición de la pieza } \\
\text { Edición y diseño } \\
10 \% \text { de los costes }\end{array}$ & $\begin{array}{l}\text { Creación digital de la obra } \\
\text { Edición y diseño } \\
80 \% \text { de los costes }\end{array}$ \\
\hline $\begin{array}{l}\text { Fase 2: } \\
\text { Comercialización }\end{array}$ & $\begin{array}{l}\text { Producción y fabricación del objeto } \\
\text { fíco }\end{array}$ & $\begin{array}{l}\text { Producción digital } \\
10 \% \text { de los costes }\end{array}$ \\
\hline $\begin{array}{l}\text { Fase 3: } \\
\text { Distribución }\end{array}$ & $\begin{array}{l}\text { Distribución física } \\
75 \% \text { de los costes }\end{array}$ & $\begin{array}{l}\text { Distribución por internet } \\
10 \% \text { de los costes }\end{array}$ \\
\hline
\end{tabular}

Figura 4. Comparativa entre las cadenas de valor de los medios físicos y on-line (Elaboración propia)

La información reflejada señala cómo los gastos se concentran en la fase de distribución en la producción de los medios físicos mientras que en los medios online la mayor inversión de capital se realiza en la fase de creación, ya que la difusión se realiza a partir de plataformas web lo que abarata esta fase.

Como producto de la industria discográfica cuya pretensión principal es la recaudación económica, ya sea de forma directa o indirecta, el vídeo musical supone un alto nivel de rentabilidad. En este sentido, la Internacional Federation of the Phonografic (2013: 9) afirma que «si bien la industria depende menos de los ingresos por ventas físicas (esta participación habría bajado del $61 \%$ de 2011 a cerca de un 58\% en 2012), los soportes físicos siguen representando la mayor parte de los ingresos de la industria». Actualmente, los soportes físicos se mantienen como el mayor generador de beneficios económicos combinados con la descarga de contenidos digitales a través de las plataformas web con licencia. La Sociedad General de Autores y Editores (2012: 31) afirma sobre las redes digitales en España que «la música a la carta con descarga vuelve a ser el primer modelo de negocio, con unos ingresos sociales de 1.705 .000 euros y un crecimiento del 65,6 \%». A nivel mundial, las ventas digitales han superado a las físicas frenando el problema de la piratería. El usuario es consciente del valor del contenido digital y abona su precio por canción, aunque se mantienen las descargas gratuitas a través del P2P (Peer to Peer), cuya tecnología convierte al 
usuario en emisor y receptor al mismo tiempo. Los contenidos digitales abarcan las descargas desde internet y la tecnología móvil, los productos de móvil, las suscripciones y las plataformas de streaming financiado por la publicidad o Add-Supported.

En la actualidad, debido a la crisis económica y al problema que supone la piratería, la promoción ha comenzado a basarse mayoritariamente en los conciertos, sobre todo en pequeñas salas, y en la difusión viral de los videoclips en Internet. En España los datos sobre el mercado discográfico reflejan esta situación. La Sociedad General de Autores y Editores (2012: 29) analiza la venta de discos en nuestro país durante 2012 y observa una tendencia descendente: «En 2012, el descenso fue del 9,2\%, y las unidades facturadas disminuyeron en un 8,3\%, hasta situarse en los 12,3 millones». Esta misma institución aporta datos económicos sobre los ingresos procedentes de los grandes conciertos y giras, que en 2012 incrementó «un 9,3\% en relación con el año 2011, gracias a acontecimientos como Rock in Rio, celebrado en Arganda del Rey (Madrid)» (SGAE, 2012: 22). Las causas de la disminución de los ingresos en taquilla se deben a la mencionada crisis económica y al aumento del IVA. Fouce (2012: 565) expone como rasgos de la crisis la caída de las ventas de discos, agravada «con la popularización exponencial de los sistemas de intercambio de archivos musicales, con la emergencia y abatimiento de una generación de programas (Kazaa, Auiogalaxy, Limewire, E-mule...)» por lo que el disco (mercancía tangible) es sustituido por la descarga musical a través de internet (mercancía intangible).

Esta crisis del mercado discográfico afecta a las industrias mundiales. Así en Estados Unidos el formato físico del CD ha descendido en volumen de ventas en favor de las descargas de los contenidos digitales. En 2002 la venta de discos en dicho país ascendía a 800 millones de copias, con la irrupción de iTunes ese mismo año se produjo una deceleración que tuvo como resultado la venta de 300 millones en 2012. De este modo se realiza un cambio en el factor creador de los beneficios económicos que se trasladan desde el disco y que se percibían desde el lanzamiento del álbum, hacia la canción, con lo que los beneficios se presentan desde que se lanza el primer single. El consumo musical basado en la canción en detrimento del disco supone un aumento de la atención por parte del usuario que revierte directamente en su revalorización social. Junto a la canción se difunde también el vídeo musical que se erige como un producto más del mercado digital susceptible de su compra en unidades a través de servicios como iTunes y otros de descarga gratuita como Spotify, Deezer y YouTube. El modelo de suscripción propuesto por las empresas anteriormente citadas supone para la industria una fuente de ingresos continuos frente al modelo tradicional basado en la venta de discos de carácter más estacional. Sin embargo, estas plataformas web cuentan con servicios gratuitos y servicios premium, en los que el usuario se beneficia de mejoras sobre los contenidos. La dificultad estriba en atraer el máximo de usuarios hacia las cuentas premium bajo suscripción de pago. 
El vídeo musical se erige como un formato autónomo e independiente, capaz de establecer su propia cadena de valor, paralela a la de la industria discográfica de la que surge como producto. Del mismo modo se evidencian los nuevos modelos de distribución y difusión de los videoclips a partir de las nuevas plataformas digitales.

El nuevo modelo de negocio para la industria fonográfica comienza a basarse en los contenidos digitales lo que supone una gradual instauración del soporte inmaterial, ya que la canción se convierte en un archivo informático comprimido que el usuario puede descargar o disfrutar en streaming, abaratando los costes de difusión de los mismos. Como señalan Miguel De Bustos y Arregocés (2006) se produce un consumo fraccionado debido a que el usuario descarga la canción que quiere escuchar y no el disco completo. Tras la escucha previa se adquieren los contenidos seleccionados, fragmentando el CD como un todo. Así, el negocio evoluciona desde lo offline hacia lo online, aunque en la actualidad subsisten ambos modelos de mercado, por lo que la industria discográfica debe buscar la rentabilidad conjunta. Existen productos que se comercializan tanto en soporte físico como en soporte digital, sin embargo, otros muchos son lanzados exclusivamente en formato digital a través de su distribución desde el sitio web de la propia empresa.

Se concluye de este modo cómo el desarrollo de las plataformas y la crisis del mercado de la música inciden en la cadena de valor del vídeo musical, sobre todo en lo relativo a las etapas de distribución y difusión. Así como se evidencian los distintos agentes implicados en la creación del videoclip como producto autónomo que genera valor económico y artístico por sí mismo, desplazado ya de su origen como mercancía asociada a la canción y al disco.

\section{Referencias}

Ariza, Marina y Gandini, Luciana (2012). El análisis comparativo cualitativo como estrategia metodológica. En: Ariza, Marina y Velasco, Laura (Coords.), Métodos cualitativos y su aplicación empírica. Por los caminos de la investigación sobre la migración internacional. México: Instituto de Investigaciones Sociales y Colegio de la Frontera Norte.

Calvi, Juan Carlos (2006). La industria de la música, las nuevas tecnologías digitales e internet. Algunas transformaciones y salto en la concentración. En Zer. Revista de Estudios de Comunicación, nº 21. País Vasco, 121-137.

Fandos, Manuel (1993). El vídeo-clip musical. En Comunicar. Revista Científica de Comunicación y Educación, ${ }^{\circ}{ }^{0}$. Huelva: Grupo Comunicar, 94-97.

Fouce, Héctor (2012). La desnudez del rey y el aire nuevo de las catacumbas. Ocaso y dinamización de la industria de la música. En: Salgado, Fernando y 
Martínez, Valentín Alejandro (Coords.), Economía de la cultura y la comunicación en la era digital. Lisboa: Media XXI.

Frith, Simon (1980). Sociología del Rock. Madrid: Júcar.

- (2006). La otra historia del Rock. Barcelona: Robinbook.

Girard, Augustin (1982). Las industrias culturales: ¿Obstáculo o nueva oportunidad para el desarrollo cultural? En: UNESCO (Ed.), Industrias culturales: El futuro de la cultura en juego. México: Fondo de Cultura Económica.

Internacional Federationof the Phonografic Industry IFPI (2013). Informe sobre música digital de la IFPI 2013. Motor de un mundo digital. Disponible en http://www.promusicae.es/documents/viewfile/90-digital-music-report-2013. Consultado el 07/04/2014.

Miguel De Bustos, Juan Carlos y Arregocés, Benjamín (2006). Industria fonográfica. Hacia un nuevo modelo de la industria musical. Telos, Cuadernos de Comunicación e Innovación, $\mathrm{n}^{0}$ 68. Disponible en http://telos.fundaciontelefonica.com/telos/articuloperspectiva.asp@idarticulo=2\&rev=68.htm. Consultado el 10/09/2013.

Pérez-Ornia, José Ramón (1991). El arte del vídeo. Introducción a la historia del vídeo experimental. Barcelona: Serbal y RTVE.

Sedeño, Ana María. (2008). El videoclip musical como formato audiovisual publicitario. Actas do $5^{0}$ Congresso da Associação Portuguesa de Ciências da Comunicação, 750-759.

Sociedad General de Autores y Editores SGAE (2012). Informe de gestión. Disponible en http://www.sgae.es/recursos/Memoria_2012/GESTION/Informe_ gestion_WEB1.pdf. Consultado el 04/11/2013

\section{Referencia de este artículo}

Rodríguez-López, Jennifer y Aguaded-Gómez, Ignacio (2015). La cadena de valor del vídeo musical: el videoclip en el circuito comercial de las industrias culturales. En: adComunica. Revista Científica de Estrategias, Tendencias e Innovación en Comunicación, $\mathrm{n}^{\circ} 9$. Castellón: Asociación para el Desarrollo de la Comunicación adComunica, Universidad Complutense de Madrid y Universitat Jaume I, 119-132. DOI: http://dx.doi.org/10.6035/2174-0992.2015.9.8. 